\title{
Stereotactic radiotherapy for early-stage non-small cell lung cancer
}

\author{
Chiara Reverberi, Marco Trovò \\ Radiotherapy Department, Santa Maria della Misericordia Hospital, Udine 33100, Italy.
}

Correspondence to: Dr. Chiara Reverberi, Radiotherapy Department, Santa Maria della Misericordia Hospital, Piazzale Santa Maria della Misericordia 15, Udine 33100, Italy. E-mail: chiarareverberi87@gmail.com

How to cite this article: Reverberi C, Trovò M. Stereotactic radiotherapy for early-stage non-small cell lung cancer. Miniinvasive Surg 2020;4:43. http://dx.doi.org/10.20517/2574-1225.2020.33

Received: 31 Mar 2020 First Decision: 9 May 2020 Revised: 24 May 2020 Accepted: 1 Jun 2020 Published: 12 Jul 2020

Academic Editor: Noriyoshi Sawabata Copy Editor: Cai-Hong Wang Production Editor: Tian Zhang

\begin{abstract}
Surgical resection is treatment of choice for early stage non-small cell lung cancer, even though 20\%-30\% of patients do not undergo surgery. Compared to conventional fractionated radiotherapy, stereotactic body radiotherapy (SBRT) has demonstrated excellent local control (LC) and overall survival (OS). Central and ultracentral lesions present higher toxicity rates after SBRT because of their proximity to mediastinal structures. Dose escalation studies have documented that 10-12 Gy per fraction is the maximal tolerable dose with acceptable rates of treatment adverse events and survival. Peripheral lesions can be safely treated with high radiotherapy dose (biologically equivalent dose of $\geq 150 \mathrm{~Gy}$ ) and a different SBRT dose schedule has showed comparable results with $L C$ rates $>90 \%$ and OS comparable to surgical resection. Elderly patients, defined as 75 years or older, are a subgroup of patients who may benefit the most from SBRT, as they have higher morbidity and mortality risks because of comorbidities and decreased lung function. At present, there are no randomized studies comparing SBRT with surgery for patients who are potential candidates for surgical removal. Retrospective studies and systematic reviews have showed encouraging results in terms of cancer-specific survival and LC.
\end{abstract}

Keywords: SBRT, ablative radiotherapy, early stage non-small cell lung cancer, NSCLC

\section{INTRODUCTION}

International guidelines suggest that the cornerstone of treatment for early stage non-small cell lung cancer (NSCLC) is surgical resection, with precise lobectomy and systematic mediastinal/hilar lymph node dissection the standard of care. Nevertheless, roughly $20 \%-30 \%$ of patients with stage I NSCLC do not undergo surgery ${ }^{[1]}$. The 5 -year cancer specific survival (CSS) rate for early-stage lung cancer patients who do not receive any treatment is around $16 \%{ }^{[2]}$. All patients need to be discussed at a multidisciplinary

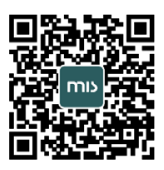


tumor board meeting involving the thoracic surgeon, lung specialist, clinical and radiation oncologist, radiologist, nuclear medicine physician and pathologist. Together, they will define the operability of the case and discuss the best treatment options. Currently, national and international guidelines purpose definitive radiotherapy as an alternative in the event patients are not candidates for surgery or if they refuse resection $^{[3,4]}$. Historically, studies have demonstrated that the local control (LC) rate with convectional radiotherapy was inadequate compared to surgery. Dose escalation studies have found that LC and survival were improved with doses $\geq 80$ Gy. Thus, several accelerated radiotherapy regimens have been tested to achieve better results in terms of outcomes and toxicity. Limiting the dose to the surrounding tissues is an important goal, particularly because early stage NSCLC patients who are not suitable for surgery, are usually fragile due to age or other comorbidities. The stereotactic body radiotherapy (SBRT) technique has been developed for the treatment of localized lung lesions because it is a highly conformal and focused ablative treatment delivered precisely to a delineated target volume over a short period. Literature data have also demonstrated that the LC rate after SBRT ranges around $85 \%-100 \%{ }^{[5]}$. The SPACE trial ${ }^{[6]}$ was the first clinical trial to compare the outcomes of SBRT $v$ s. conventional fractionated radiotherapy: it randomized 102 patients to receive 66 Gy of SBRT over three fractions or 3D conformal radiotherapy of 70 Gy over 35 fractions. It demonstrated non-inferiority of SBRT with no difference in progression free survival (PFS) and overall survival (OS) among groups with a comparable toxicity profile. Recently, the CHISEL trial ${ }^{[7]}$ proved that SBRT had a favorable toxicity profile and achieved superior LC compared to conventional radiotherapy: the 2-year LC rates were $89 \%$ vs. $65 \%$, respectively. Thus, SBRT is considered the treatment of choice for patients with early stage NSCLC who are not candidates for surgery and it has seen widespread uptake in clinical practice. Despite rapid and wide adoption of SBRT, there still exists substantial variation in patient selection, staging, radiotherapy technique (planning and delivery), the prescribed dose and dose per fraction, duration and modality of follow-up. This paper aims to review the main questions regarding the use of SBRT in clinical practice, by reviewing the most important data published so far. We discuss the maximum tolerable dose of SBRT, toxicity, LC and OS outcomes for peripheral, central and ultra-central lesions, and we investigate its effectiveness and tolerability in the elderly subpopulation. Finally, we review the most relevant data comparing SBRT with surgery.

\section{Peripheral lesions}

A peripheral lesion is defined as a non-central lesion: it includes all tumors arising from the lung parenchyma at least $2 \mathrm{~cm}$ from the principal bronchial tree. Several dose escalations studies have demonstrated that LC is improved by delivering a higher biological effective dose (BED) to the target. The main stone study published by Onishi et al. ${ }^{[8]}$ reported that LC highly correlates with radiation dose. The authors documented that the 5-year LC was statistically and significantly higher ( $91.6 \% v s .57 .1 \%)$ in the group of patients treated with a $B E D \geq 100$ Gy compared to those treated with less than 100 Gy (assuming lung cancer $\alpha / \beta=10$ ). These observations were confirmed by subsequent prospective studies. In the series published by researchers from Washington University, it was found that higher maximum doses led to higher rates of local tumor control. Moreover, on multivariate analysis, only maximum tumor doses correlated with tumor control ${ }^{[9]}$.

Patients with peripheral lesions had an excellent outcome after SBRT as the 2-year LC and OS rates were 95\% and 57.6\%, respectively. Patients with peripheral lesions tolerate larger doses per fraction, even in those considered unfit for surgery because of comorbidities and poor lung function [Table 1].

The rate of 2-year toxicity-free interval, after SBRT dose of 60-66 Gy/3 fractions (20-22 Gy per fraction) given over a period of 1.5-2 weeks, was significantly higher in patients with peripheral lesions compared to central lesions at $83 \%$ and $54 \%$, respectively ${ }^{[10]}$. No treatment-related deaths were observed for high dose SBRT (BED 150 Gy) in the Radiation Therapy Oncology Group (RTOG) 0236 trial, and the Grade 3-4 toxicity rate was $27.2 \%$. The RTOG 0236 trial involved 59 patients with peripheral T1-2 $(<5 \mathrm{~cm})$ NSCLC 
Table 1. Peripheral lesion

\begin{tabular}{|c|c|c|c|}
\hline Study & Fractionation & Toxicity (incidence of adverse events) & Survival rates \\
\hline Timmerman et al. ${ }^{[10]}$ (RTOG 0236) & $60-66 \mathrm{~Gy} / 3 \mathrm{fr}$ & Grade 3-5: $20 \%$ & $\begin{array}{l}\text { 2-year LC: } 95 \% \\
\text { 2-year OS: } 54.7 \%\end{array}$ \\
\hline Timmerman et al. ${ }^{[11]}$ (RTOG 0618) & $54 \mathrm{~Gy} / 3 \mathrm{fr}$ & $\begin{array}{l}\text { Grade } 3: 12.7 \% \\
\text { Grade } 4: 3.6 \% \\
\text { No Grade } 5 \text { toxicity }\end{array}$ & $\begin{array}{l}\text { 3-year LC: } 97.6 \% \\
\text { 3-year OS: } 55.8 \%\end{array}$ \\
\hline \multirow[t]{3}{*}{ Guckenberger et al. ${ }^{[14]}$} & $45 \mathrm{~Gy} / 3 \mathrm{fr}$ & & LC around $90 \%$ \\
\hline & $48 \mathrm{~Gy} / 4 \mathrm{fr}$ & & LC around $90 \%$ \\
\hline & $54 \mathrm{~Gy} / 3 \mathrm{fr}$ & & \\
\hline \multirow[t]{2}{*}{ Videtic et al. ${ }^{[15]}$ (RTOG 0915) } & $34 \mathrm{~Gy} / 1 \mathrm{fr}$ & Toxicity: $16 \%$ & 2-year OS: 61.3\% \\
\hline & $48 \mathrm{~Gy} / 4 \mathrm{fr}$ & Toxicity: $12 \%$ & 2-year OS: $77.7 \%$ \\
\hline \multirow[t]{2}{*}{ Singh et al. ${ }^{[16]}$} & $30 \mathrm{~Gy} / 1 \mathrm{fr}$ & $\begin{array}{l}\text { Thoracic Grade 3: } 16 \% \\
\text { No Grade 4-5 }\end{array}$ & $\begin{array}{l}\text { 2-year LC: } 94.9 \% \\
2 \text {-year OS: } 73 \%\end{array}$ \\
\hline & $60 \mathrm{~Gy} / 3 \mathrm{fr}$ & $\begin{array}{l}\text { Thoracic Grade 3: } 12 \% \\
\text { No Grade 4-5 }\end{array}$ & $\begin{array}{l}\text { 2-year LC: } 97.1 \% \\
2 \text {-year OS: } 62 \%\end{array}$ \\
\hline \multirow[t]{2}{*}{ Cummings et al. ${ }^{[18]}$} & $30 \mathrm{~Gy} / 1 \mathrm{fr}$ & Grade 3 (lung toxicity): $4.6 \%$ & $\begin{array}{l}1 \text { and 2-year LC: } 95 \%-88 \% \\
1 \text { and 2-year OS: } 84 \%-61 \% \\
\text { 5-year OS: } 17 \%\end{array}$ \\
\hline & $50 \mathrm{~Gy} / 5 \mathrm{fr}$ & Grade 3 (lung toxicity): $7.1 \%$ & $\begin{array}{l}1 \text { and } 2 \text {-year LC: } 93 \%-90 \% \\
1 \text { and 2-year OS: } 85 \%-70 \% \\
5 \text {-year OS: } 39 \%\end{array}$ \\
\hline \multirow[t]{3}{*}{ Stephans et al. ${ }^{[19]}$} & $54 \mathrm{~Gy} / 3 \mathrm{fr}$ & $\begin{array}{l}\text { Lung toxicity: } 5.1 \% \\
\text { Chest wall toxicity: } 23.7 \%\end{array}$ & 2-year LF: 13.1\% \\
\hline & $30-34 \mathrm{~Gy} / 1 \mathrm{fr}$ & $\begin{array}{l}\text { Lung toxicity: } 3.2 \% \\
\text { Chest wall toxicity: } 8.6 \%\end{array}$ & 2-year LF: 21\% \\
\hline & $48-50 \mathrm{~Gy} / 4-5 \mathrm{fr}$ & $\begin{array}{l}\text { Lung toxicity: } 3.8 \% \\
\text { Chest wall toxicity: } 7.7 \%\end{array}$ & 2-year LF: 15.5\% \\
\hline
\end{tabular}

Fr: fraction; LC: local control; OS: overall survival; LF: local failure

lesions who were not candidates for surgery (unsatisfactory lung function tests: forced expiratory volume in $1 \mathrm{sec}-\mathrm{FEV} 1-<40 \%$ ), and received $54 \mathrm{~Gy} / 3$ fractions of SBRT over 1.5-2 weeks. After a median follow-up of 34.4 months, the estimated 3-year LC and OS were $97.6 \%$ and $55.8 \%$, respectively ${ }^{[11]}$.

Patient selection can make the difference in toxicity and survival data: healthier patients reported less toxicity, better local control and were able to tolerate treatment (total dose delivered and dose per fraction). The RTOG 0618 trial enrolled patients with T1-2 $(<5 \mathrm{~cm})$ tumors that were potentially operable (the median FEV1 72.5\%, range: 38\%-136\%) to receive 54 Gy/3 fractions (18 Gy each fraction) of SBRT over 1.5-2 weeks. After a median follow-up of 48.1 months, 2-year LC was $96 \%$ and 4 -year OS was $56 \%$, no Grade 4-5 toxicity was registered, and the incidence of Grade 3 toxicity was $15 \%{ }^{[12]}$. LC was excellent: the 3 - and 5 -year LC rates were $96 \%$ and 93\%, respectively, for fit patients who refused surgery. The SBRT dose was 60 Gy/5 fractions (12 Gy per fraction) for peripheral lesions not adjacent to the chest wall, and 50 Gy/5 fractions (10 Gy per fraction) for peripheral lesions or close to the chest wall ${ }^{[13]}$. The Advisory Committee on Radiation Oncology Practice (ACROP) consensus conference ${ }^{[14]}$ suggested that patients who are not candidates for surgery might benefit from PTV minimum doses ranging from 105 Gy to 113 Gy. Consequently, the recommended fractionations were $45 \mathrm{~Gy} / 3$ fractions ( $15 \mathrm{~Gy}$ per fraction) for peripherally located lesions (> $1 \mathrm{~cm}$ from chest wall) and $48 \mathrm{~Gy} / 4$ fractions (12 Gy per fraction) for lesions having broad chest wall contact. This regimen can achieve a $90 \%$ local control rate and has an acceptable toxicity profile. The consensus conference also suggested considering 54 Gy/3 fractions (18 Gy per fraction) as the maximum tolerable dose for patients who refused surgery, without severe comorbidities and have favorable long-term life expectancies.

The RTOG 0915/North Central Cancer Treatment Group N0927 was a randomized phase II trial designed to evaluate toxicity related to two regimens for peripheral lesions: $34 \mathrm{~Gy}$ in a single fraction and 48 Gy in four consecutive daily fractions. Grade 3 toxicity rates at 1 year after treatment was similar among groups. 
In particular, the authors found no difference in chest wall severe adverse events. Compared to RTOG 0236, the rate of toxicity was lower and outcome results were comparable as the 2-year OS rate was $61.3 \%$ in 34 Gy/1 fraction schedule and $77.7 \%$ in fractionated SBRT, respectively ${ }^{[15]}$. No significant difference in LC, OS, adverse events and lung function in patients treated with $30 \mathrm{~Gy}$ in a single fraction $v s .60 \mathrm{~Gy} / 3$ fractions (20 Gy per fraction) was reported. Toxicity rate was $16 \%$ in the single fraction arm vs. $12 \%$ in the multifractions regimen ${ }^{[16]}$. Retrospective propensity-matched comparison between the 3 fractions regimen (total dose 60 Gy, 20 Gy per fraction) and the 5 fractions schedule (total dose 50 Gy, 10 Gy per fraction), showed no significant differences in OS, PFS, local failure and distant relapse at 2 years ${ }^{[17]}$. No significant conclusions about optimal dose fractionation in peripheral lesions can be derived so far. Both single and multi-fraction SBRT produce comparable outcomes and limited adverse events. The 1- and 2-year LC rate ranged between 93\%-95\% and 88\%-90\% in patients treated with single fraction SBRT (30 Gy/1 fraction) over a fractionated regimen (50 Gy/5 fractions: 10 Gy per fraction). OS was significantly longer in patients treated with fractionated SBRT (1- and 2-year OS rates were $84 \%$ and $61 \%$ with one fraction group $v$ s. $85 \%$ and $70 \%$ in the fractionated schedule, $P=0.01$ ), unless the baseline tumor size was imbalanced across groups and the fractionated schedule cohort presented a larger treatment volume ${ }^{[18]}$. Results of a large single institution series suggested that $54 \mathrm{~Gy} / 3$ fractions (18 Gy per fraction) of SBRT led to improved LC compared to 30-34 Gy/single fraction and 48-50 Gy/4-5 fractions (10-12 Gy per fraction). The lung toxicity rate (any Grade) was slightly higher with the 3 fractions schedule at $5.1 \%$ vs. $3.2 \%$ and $3.8 \%$ in the single and $4-5$ fractions schedule, respectively. Moreover, chest wall toxicity was more common in the 3 fractions (23.7\%) compared to $8.6 \%$ and $7.7 \%$ in the single and $4-5$ fractions schedule, respectively ${ }^{[19]}$.

\section{Central and ultra-central lesions}

\section{Central lesions}

Currently, lung tumors located around the proximal bronchial tree are defined as "Central". This refers to the zone $2 \mathrm{~cm}$ distal to the trachea, carina, and major lobar bronchi up to their first bifurcation. Patients treated for central lesions were more likely to experience treatment related side effects, as demonstrated by a phase II trial, which enrolled NSCLC patients who were clinically staged as T1-3 $(<7 \mathrm{~cm})$, not candidates for surgery, and received 60-66 Gy/3 fractions (20-22 Gy each fraction) of SBRT. The authors reported that the peri-hilar/peri-central tumor location was a stronger predictor of toxicity in both uniand multi-variate analyses $(P=0.004)^{[10]}$. Medically inoperable patients with central lesions were recruited in a prospective phase I/II trial to investigate the toxicity and efficacy of four dose levels (from 9 to 12 Gy per fraction), measured as an objective 2-year LC rate $>80 \%$. They defined all lesions located within $2 \mathrm{~cm}$ around the proximal bronchial tree, or $5 \mathrm{~mm}$ by the mediastinal pleura or parietal pericardium as central. The reported acute Grade 3-4 toxicity rate was $6 \%$, while $27 \%$ developed late Grade 3 toxicity and $16 \%$ had grade $4-5$ late adverse events ${ }^{[20]}$. Thereafter, a phase I-II dose-escalation study (RTOG 0813) was designed to determine the maximum tolerable dose for central tumors. Patients were assigned to receive SBRT in a 5 fractions schedule, with each dose per fraction ranging from 10-12 Gy; dose limiting toxicity was defined as any Grade $\geq 3$ adverse event that occurred in the first year after treatment. The maximum tolerable dose was 12 Gy per fraction (total dose $60 \mathrm{~Gy}$ ) which reported 7.2\% Grade $\geq 3$ toxicity $^{[21]}$.

Several studies have investigated the optimal dose of treatment for centrally located lesions by balancing survival outcomes and toxicity. SBRT for patients with central tumors achieved markedly better local control compared to conventional radiotherapy. A prospective, phase II trial investigated an alternative treatment schedule to the $60 \mathrm{~Gy} / 3$ fractions scheme, which is not recommended in central lesions due to its high toxicity rate. Patients who were medically inoperable were treated with $55 \mathrm{~Gy} / 5$ fractions (11 Gy per fraction) of SBRT achieved an estimated 2-year LC and OS of $85 \%$ and $43 \%$, respectively. With a 2 -year local control rate $>80 \%$, the phase II trial achieved its primary end point after a median follow up of 17 months. Most of the tumors were located centrally (84\%), within $2 \mathrm{~cm}$ of the proximal bronchial tree; $16 \%$ were located within $5 \mathrm{~mm}$ of the mediastinal or pericardial pleura (ultra-central lesions) ${ }^{[20]}$. The 
Table 2. Central lesion

\begin{tabular}{|c|c|c|c|}
\hline Study & Fractionation & Toxicity (incidence of adverse events) & Survival rates \\
\hline Roach et $\left.a\right|^{[20]}$ & $55 \mathrm{~Gy} / 5 \mathrm{fr}$ & $\begin{array}{l}\text { Acute Grade 3-4: 6\% } \\
\text { Late Grade 3: } 27 \% \\
\text { Late Grade } 4-5: 16 \%\end{array}$ & $\begin{array}{l}\text { 2-year LC: } 85 \% \\
\text { 2-year OS: } 43 \%\end{array}$ \\
\hline Bezjak et al. ${ }^{[21]}$ (RTOG 0813) & $60 \mathrm{~Gy} / 5 \mathrm{fr}$ & Grade $\geq 3: 7.1 \%$ & $\begin{array}{l}\text { 2-year LC: } 87.9 \% \\
\text { 2-year OS: } 72.7 \%\end{array}$ \\
\hline \multicolumn{4}{|l|}{ Ultra-central lesion } \\
\hline Tekatli et al. ${ }^{[22]}$ & $60 \mathrm{~Gy} / 12 \mathrm{fr}$ & $\begin{array}{l}\text { Grade } 3: 38 \% \\
\text { Possible treatment related death: } 21 \%\end{array}$ & $\begin{array}{l}\text { Median OS: } 15.9 \text { months } \\
\text { 3-year OS: } 20.1 \%\end{array}$ \\
\hline Zhao et al. ${ }^{[23]}$ & $60 \mathrm{~Gy} / 8 \mathrm{fr}$ & $\begin{array}{l}\text { Grade } 3: 5.1 \% \\
\text { No Grade } 4-5\end{array}$ & 1 and 3-year LC: $98 \%$ \& 84\% \\
\hline
\end{tabular}

Fr: fraction; LC: local control; OS: overall survival

RTOG 0813 Phase II trial indicated that 12 Gy per fraction was the maximum tolerable dose for medically inoperable patients with centrally located, early stage tumors. Outcome results were comparable with the results of patients treated for peripheral lesions. Seventy-one patients who were not fit for surgery, mostly elderly and with comorbidities, were recruited to receive SBRT of 60 Gy delivered in 5 fractions (12 Gy per fraction) vs. $57.5 \mathrm{~Gy} / 5$ fractions (11.5 Gy per fraction), and 65\% of cancers were staged as T1. The 2-year LC rate was $87.9 \%$ in the 12 Gy per fraction cohort $v$ s. $89.4 \%$ for the 11.5 Gy per fraction, and the 2-year OS rate was $72.7 \%(12 \mathrm{~Gy})$ vs. $67.9 \%(11 \mathrm{~Gy})^{[21]}$ [Table 2].

\section{Ultra-central lesions}

"Ultra-central" lesions are defined as tumors with planning target volume (PTV) that mostly overlaps the mediastinal space. A retrospective study evaluated if ultra-central lesions were at higher risk for developing toxicity. Forty-seven ultra-central lesions were treated with 60 Gy/12 fractions (5 Gy each fraction) of SBRT with a median total PTV of $104.5 \mathrm{~cm}^{3}$ (range 17.7-508.5), and the tumor diameter exceeded $5 \mathrm{~cm}$ in $60 \%$ of patients. They reported a $38 \%$ rate of Grade 3 toxicity and a $21 \%$ rate of "possible" and "likely" treatmentrelated death, including $15 \%$ of fatal pulmonary hemorrhage ${ }^{[22]}$.

In clinical practice, mediastinal organs at risk have resulted in compromising PTV coverage in SBRT treatment of ultra-central lesions. A retrospective study reviewed 98 patients with central and ultracentral lesions treated with $60 \mathrm{~Gy} / 8$ fractions (7.5 Gy per fraction) of SBRT. Outcomes for the subgroup of patients with ultra-central lesions were compared to the group of patients with central lesions whose PTV did not cover mediastinal structures: no difference in beneficial outcomes as well as adverse events were registered. The median PTV volume was $25.7 \mathrm{cc}$ (range 5.1-134.5 cc) for central lesions and $42.1 \mathrm{cc}$ (range 6.6-184.8 cc) for ultra-central. After a median follow-up of 22.9 months, LC rates at 1- and 2-years were 97.8 and $93.7 \%$. On multi-variate analysis, the internal target volume (ITV) was a prognostic factor for local control $(P=0.001)$. Generally, the cumulative incidence of Grade 3 toxicity was low $(5.1 \%)$ and no severe esophageal or cardiac toxicity was registered ${ }^{[23]}$ [Table 2].

Due to the very high toxicity rates reported, we do not recommend SBRT as an option in patients affected by early-stage NSCLC when the target volume overlaps mediastinal structures.

\section{Elderly population}

Elderly patients, defined as 75 years old or older, are a subgroup of patients who may benefit from SBRT due to higher morbidity and mortality risks related to surgery because of comorbidities and decreased lung function. 62,213 early stage NSCLC patients older than 60 were reviewed using the Surveillance, Epidemiology and End Results database. Data suggested that surgery declined sharply from being the treatment of choice in $81 \%$ of patients in the 60-64 years old group to only $21 \%$ of patients older than 90 years $^{[24]}$. Compared to historical outcomes for surgery in the elderly, SBRT is considered to show similar 
survival even though its toxicity rate is well below that of morbidity rates after surgery. Outcomes of 772 early stage NSCLC patients treated with 50 Gy/4 fractions (12.5 Gy per fraction) of SBRT, or in cases of central lesions, $70 \mathrm{~Gy} / 10$ fractions (7 Gy per fraction), were analyzed to verify safety in the elderly population. It was found that the elderly group had no significant difference in PFS, OS and toxicity compared to the patients younger than 75 . After a median follow-up of 55 months, the cumulative incidence of loco-regional failure was $17.3 \%$. The 1-, 3- and 5-year OS rates for patients $\geq 75$ years were $86 \%, 57.5 \%$ and $39.5 \%$, respectively. No Grade $4-5$ toxicity was registered, and Grade 3 toxicity rate was comparable (ranging around 1-2\%): the group of patients older than 75 did not differ from others ${ }^{[25]}$. SBRT can thus be very safely and effectively utilized in patients older than 80 for Stage I tumors at a median ablative dose (BED $\geq 100 \mathrm{~Gy}$ ) of 54 Gy/3 fractions (18 Gy per fraction) with 1- and 2-year LC rate of 100\% and $92.3 \%$, and no reported toxicity Grade $2-5^{[26]}$. An observational study reviewed 58 consecutive patients $\geq 80$ years who received SBRT for early-stage NSCLC. Overall, the 3 -year OS rate was $56.4 \%$, suggesting the efficacy of SBRT; patients with Karnofsky performance status $\geq 75$ had improved 3-year CSS and OS rates (99.4\% and $91.9 \%$, compared to $47.8 \%$ and $23.6 \%$ in patients with $\mathrm{KPS}<75$, respectively $)^{[27]}$.

Oncological outcomes and toxicity rates were analyzed in NSCLC Stage I patients older than 90 years and treated with SBRT at a dose of $50 \mathrm{~Gy} / 5$ fractions daily (10 Gy per fraction). Nineteen patients were identified: the median age was 91.6 years, the median tumor size was $2.1 \mathrm{~cm}$, and $31.6 \%$ were central lesions. Two-year rates of local failure and OS were 5.6\%, and $47.8 \%$; no Grade 3 toxicity was registered ${ }^{[28]}$.

\section{SBRT vs. surgery}

SBRT is a noninvasive, well-tolerated ablative treatment perceived as an attractive option even for patients who are potentially fit for surgery. For this reason, three randomized clinical trials (ROSEL, STARS, ACOSOG Z4099) have been launched to compare SBRT with lobectomy in patients deemed medically operable. Each of this trial has been closed prematurely because of scarce accrual of results, although a pooled analysis of the ROSEL and STARS trials reported reduced morbidity and no inferior OS and PFS of SBRT compared to lobectomy. The estimated 3-year OS rate was $95 \%$ for SBRT $v$ s. $79 \%$ in the surgical group $(\mathrm{HR}=0.14,95 \% \mathrm{CI}: 0.017-1.19)$. It must be emphasized that the small sample size is such that this data not reliable ${ }^{[29]}$. Retrospective studies reported comparisons amongst similar groups of patients treated with surgery or SBRT, even though most authors reported unmatched baseline characteristics. Patients treated with surgery were more likely to be fit, younger, healthier, and have more favorable lung function; on the other hand, the SBRT group proportionally had more T1 tumors.

According to the American Society of Clinical Oncologists ${ }^{[30]}$, for patients with standard operative risk ( $1.5 \%$ mortality rate) and Stage I NSCLC, SBRT is not recommended as an alternative to surgery outside clinical trials. The standard operative risk reached $4.4 \%$ in patients aged 81 years or more, even though age, sex, cardiovascular and pulmonary comorbidities, and patients' functional status are factors influencing peri-operative risk.

\section{SBRT vs. lobar resection}

Lobectomy represents the standard of care for early stage lung cancer with 3- and 5-years OS rate of approximately $82 \%$ and $66 \%$, respectively. The minimally invasive approach (video-assisted thoracoscopic surgery) has showed non-inferior results in survival and fewer peri-operative complications and morbidity compared to open lobectomy ${ }^{[31]}$. In the absence of clinical trials, more reliable data has come from a metaanalysis of propensity score-matched analysis comparing lobectomy to SBRT. OS rate at 1 year was similar among groups, but data favored surgery at 3 years. Nevertheless, CSS rates were comparable in both arms, which indicates that SBRT patients may be less healthy and die of non-cancer causes ${ }^{[32]}$. A systematic review investigated the efficacy of both SBRT and lobectomy for Stage I-II disease and found no difference in 1-year survival rate. However, long-term results indicate a benefit of lobectomy over SBRT: lobectomy 
significantly improved 3-year OS (OR $=2.11,95 \% \mathrm{CI}: 1.55-2.86)$ and 5-year OS (OR $=2.40,95 \% \mathrm{CI}$ : 1.71 3.36), 3-year CSS (OR $=1.94,95 \% \mathrm{CI}: 1.05-3.57)$ and 3 year PFS $(\mathrm{OR}=1.63,95 \% \mathrm{CI}: 1.12-2.36)^{[33]}$.

Many observational studies suggest that the survival advantages reported from lobectomy could have been a consequence of treatment selection criteria. Data on patients deemed fit for surgery but treated with SBRT have suggested that OS ( $\mathrm{HR}=1.68,95 \% \mathrm{CI}: 0.72-3.90)$ and PFS ( $\mathrm{HR}=0.61, P=0.09)$ were comparable to that from surgery. Performance status was also found to impact significantly on $\mathrm{OS}^{[34]}$. The pattern of failure studied in a t-matched comparison study was similar between patients who underwent an optimal surgical operation and those who received SBRT. There was a trend of a distant-recurrence free interval in favor of lobectomy because of reported occult nodal involvement. Nodal metastases have been detected in $20 \%$ of patients treated with surgery and almost $15 \%$ received adjuvant systemic therapy (pN2). Surgical patients had higher OS rate $(63.5 \%$ vs. $29.6 \%, P<0.0001)$ with no difference in CSS. The rate of complete response was similar, whereas the 4-year LC rate was significantly higher in resected patients (98.7\% vs. $93.6 \% P=0.015)^{[35]}$. Surgery had a 1 in 6 chance of discovering occult nodal metastasis, while only 1 in 9 would benefit from adjuvant chemotherapy. Adjuvant chemotherapy improved OS in patients with nodal involvement, but surgery (either lobectomy or sub-lobar resection) was related with severe adverse events and mortality rate. A meta-analysis confirmed that patients who underwent surgery had better OS over SBRT [HR $\left.=1.48,(95 \% \mathrm{CI}: 1.26-1-72), P<0.001, I^{2}=80.5 \%\right]$ but there was no difference in lung cancer-specific survival ${ }^{[36]}$. Lobectomy demonstrated survival advantages over SBRT even when data analysis had been restricted by exclusion of older patients, poor performance status and clinical stage IB. A meta-analysis noted that SBRT treatment was delayed compared to surgery. A possible explanation is that patients who are not candidates for surgery may require repeat CT scans in order to demonstrate increase of the unbiopsied nodule's size ${ }^{[37]}$. Surgery (lobectomy and sub-lobar-resection) showed statistically superior outcomes for OS, CSS, PFS and loco-regional control compared to SBRT in both matched and un-matched cohorts for mid- and long-term outcomes. Distant control was not statistically improved by surgery but there was a trend suggesting lobectomy could show an advantage in the long term. The extent of favorable long-term outcomes in surgery may be influenced however, by imbalances in baseline patient characteristics, preoperative comorbidities or tumor characteristics ${ }^{[38]}$.

\section{SBRT vs. limited resection}

Detection of early stage lung cancer is increasing due to the development of diagnostic imaging, and clinicians have to face difficult treatment decisions, particularly in older patients with comorbidities and poor lung function. Less invasive procedures such as SBRT and limited lung resection (wedge, segmentectomy) provide a good alternative because they are better tolerated and have fewer adverse events. Segmentectomy is an anatomic lung resection in which interlobar and parenchymal nodes are identified and removed for pathology; wedge resection is a non-anatomic resection without nodal sampling. SBRT and wedge resections have similar survival outcomes, while the OS and CSS rates supported segmentectomy over SBRT, probably due to patient characteristics. Lung adverse events were reported more frequently after surgery $(28 \% v \text { s. } 14 \%, P<0.001)^{[39]}$. Patients ineligible for lobectomy could be candidates for wedge resection or SBRT, unless SBRT patients have more comorbidities and are older; no statistical difference in loco-regional recurrence, distant metastasis, and PFS were observed between groups. In an unmatched cohort analysis, there was a trend towards decreased local recurrence in SBRT over wedge resection: $4 \%$ vs. $20 \%(P=0.07)$. OS was also higher in the wedge resection arm $(87 \%$ with surgery $v s .72 \%$ in SBRT, $P=0.01$ ) but the CSS was equivalent ( $93 \%$ in SBRT vs. $94 \%$ with wedge). The authors suggested that the reduced OS in the SBRT arm could be related to both a higher rate of comorbidities before treatment, and complications and mortality rate post-treatment ${ }^{[40]}$. Sub-lobar resection for Stage I NSCLC showed survival advantages over SBRT in a propensity-score matched analysis with 1-and 2-year OS rates of $92 \%$ and $82 \%$. Moreover, even though segmental resection showed better OS vs. wedge resection, both of them have survival advantages over SBRT of a median dose of 30-66 Gy in 2-8 fractions. The 1-, 2-, 3- and 5-year 
relative survival rates were $96 \%, 90 \%, 84 \%$ and $71 \%$ for sub-lobar resection compared to $93 \%, 78 \%, 65 \%$ and $46 \%$ respectively for $\mathrm{SBRT}^{[41]}$. Moreover, a comparative analysis among patients Stage IA treated with SBRT or wedge resection found the SBRT cohort experienced lower survival compared to wedge resection: 5-year OS rate was 30\% vs. 55.2\% $(P<0.001)$ in unmatched analysis and still remained significantly in favor of surgery after adjustment for covariates $(31 \% v s .49 .9 \%, P<0.001)^{[42]}$.

\section{CONCLUSION}

Early stage non-small cell lung cancer patients have excellent 5-year survival rates of $60-80 \%$ if treated. The standard of care is lobectomy, but surgery is not always an option. SBRT delivers a high conformal ablative dose to the target, resulting in local control with an acceptable toxicity profile. Randomized clinical trials have tried to investigate SBRT for patients who are not candidates for surgical resection, and have showed encouraging results not inferior to surgery. Unfortunately, the trials designed for testing SBRT in patients who are potentially operable have been terminated for scarce accrual of results. Many systematic reviews and meta-analysis have tried to answer the question whether SBRT can be equal to surgery in fit patients, but results are not definitive. Therefore, SBRT is an effective and safe alternative for patients with Stage I-II NSCLC who are not candidates for surgery or who refuse surgical treatment.

\section{DECLARATIONS}

\section{Authors' contributions}

Conception and design, acquisition of data, analysis and interpretation of data: Reverberi C, Trovò M

\section{Availability of data and materials}

Not applicable.

\section{Financial support and sponsorship}

None.

\section{Conflicts of interest}

Both authors declared that there are no conflicts of interest.

\section{Ethical approval and consent to participate}

Not applicable.

\section{Consent for publication}

Not applicable.

\section{Copyright}

(c) The Author(s) 2020.

\section{REFERENCES}

1. McGarry RC, Song G, des Rosiers P. Observation-only management of early stage, medically inoperable lung cancer: poor outcome. Chest 2002;121:1155-8.

2. Raz DJ, Zell JA, Ou SH. Natural history of stage I non-small cell lung cancer: implications for early detection. Chest 2007;132:193-9.

3. National Comprehensive Cancer Network. NCCN Clinical Practice Guidelines in Oncology, Non-Small Cell Lung Cancer, version 3. 2020. Available from: https://www.nccn.org/ [Last accessed on 12 Jun 2020]

4. Postmus P, Kerr K, Oudkerk M, Senan S, Waller D, et al. Early and locally advanced non-small-cell lung cancer (NSCLC): ESMO Clinical Practice Guidelines for diagnosis, treatment and follow-up. Ann Oncol 2017;28:iv1-21.

5. Robinson CG, Bradley JD. The treatment of early-stage disease. Semin Radiat Oncol 2010;20:178-85.

6. Nyman J, Hallqvist A, Lund JA Brustugun OT, Bergman B, et al. SPACE - A randomized study of SBRT vs conventional fractionated radiotherapy in medically inoperable stage I NSCLC. Radiother Oncol 2016;121:1-8. 
7. Ball D, Mai GT, Vinod S, Babington S, Ruben J, et al. Stereotactic ablative radiotherapy versus standard radiotherapy in stage 1 nonsmall-cell lung cancer (TROG 09.02 CHISEL): a phase 3, open-label, randomised controlled trial. Lancet Oncol 2019;20:494-503.

8. Onishi H, Shirato H, Nagata Y, Hiraoka M, Fujino M, et al. Hypofractionated stereotactic radiotherapy (HypoFXSRT) for stage I nonsmall cell lung cancer: updated results of 257 patients in a Japanese multi-institutional study. J Thorac Oncol 2007;2:S94-100.

9. Bradley JD, El Naqa I, Drzymala RE, Trovo M, Jones G, et al. Stereotactic body radiation therapy for early-stage non-small-cell lung cancer: the pattern of failure is distant. Int J Radiat Oncol Biol Phys 2010;77:1146-50.

10. Timmerman R, McGarry R, Yiannoutsos C, Papiez L, Tudor K, et al. Excessive toxicity when treating central tumors in a phase ii study of stereotactic body radiation therapy for medically inoperable early-stage lung cancer. J Clin Oncol 2006;24:4833-9.

11. Timmerman R, Paulus R, Galvin J, Michalski J, Straube W, et al. Stereotactic body radiation therapy for inoperable early stage lung cancer. JAMA 2010;303:1070-6.

12. Timmerman RD, Paulus R, Pass HI, Gore EM, Edelman MJ, et al. Stereotactic body radiation therapy for operable early-stage lung cancer: findings from the NRG oncology RTOG 0618 trial. JAMA Oncol 2018;4:1263-6

13. Eriguchi T, Takeda A, Sanuki N, Tsurugai Y, Aoki Y, et al. Stereotactic body radiotherapy for operable early-stage non-small cell lung cancer. Lung Cancer 2017;109:62-7.

14. Guckenberger M, Andratschke N, Dieckmann K, Hoogeman MS, Hoyer M, et al. ESTRO ACROP consensus guideline on implementation and practice of stereotactic body radiotherapy for peripherally located early stage non-small cell lung cancer. Radiother Oncol 2017; 124:11-7.

15. Videtic GM, Hu C, Singh AK, Chang JY, Parker W, et al. A randomized phase 2 study comparing 2 stereotactic body radiation therapy schedules for medically inoperable patients with stage I peripheral non-small cell lung cancer: NRG Oncology RTOG 0915 (NCCTG N0927). Int J Radiat Oncol Biol Phys 2015;93:757-64.

16. Singh AK, Gomez-Suescun JA, Stephans KL, Bogart JA, Hermann GM, et al. One versus three fractions of stereotactic body radiation therapy for peripheral stage I to II non-small cell lung cancer: a randomized, multi-institution, phase 2 trial. Int J Radiat Oncol Biol Phys 2019;105:752-9.

17. Ma SJ, Cummings M, Serra LM, Syed YA, Hermann GM, et al. Three- versus five-fraction regimens of stereotactic body radiotherapy for peripheral early-stage non-small-cell lung cancer: a two-institution propensity score-matched analysis. Clin Lung Cancer 2018;19:e297302.

18. Cummings MA, Ma SJ, Hermann G, Serra L, Syed Y, et al. Comparison of single- and five-fraction regimens of stereotactic body radiation therapy for peripheral early-stage non-small-cell lung cancer: a two-institution propensity-matched analysis. Clin Lung Cancer 2018;19:511-7.

19. Stephans KL, Woody NM, Reddy CA, Varley M, Magnelli A, et al. Tumor control and toxicity for common stereotactic body radiation therapy dose-fractionation regimens in stage I non-small cell lung cancer. Int J Radiat Oncol Biol Phys 2018;100:462-9.

20. Roach MC, Robinson CG, DeWees TA, Ganachaud J, Przybysz D, et al. Stereotactic body radiation therapy for central early-stage NSCLC: results of a prospective phase I/II trial. J Thorac Oncol 2018;13:1727-32.

21. Bezjak A, Paulus R, Gaspar LE, Timmerman RD, Straube WL, et al. Safety and efficacy of a five-fraction stereotactic body radiotherapy schedule for centrally located non-small-cell lung cancer: NRG Oncology/RTOG 0813 Trial. J Clin Oncol 2019;37:1316-25.

22. Tekatli H, Haasbeek N, Dahele M, De Haan P, Verbakel W, et al. Outcomes of hypofractionated high-dose radiotherapy in poor-risk patients with "Ultracentral" non-small cell lung cancer. J Thorac Oncol 2016;11:1081-9.

23. Zhao Y, Khawandanh E, Thomas S, Zhang S, Dunne EM, et al. Outcomes of stereotactic body radiotherapy 60 Gy in 8 fractions when prioritizing organs at risk for central and ultracentral lung tumors. Radiat Oncol 2020;15:50.

24. Dalwadi SM, Szeja SS, Bernicker EH, Butler EB, Teh BS, et al. Practice patterns and outcomes in elderly stage I non-small-cell lung cancer: a 2004 to 2012 SEER analysis. Clin Lung Cancer 2018;19:e269-76.

25. Brooks ED, Sun B, Zhao L, Komaki R, Liao Z, et al. Stereotactic ablative radiation therapy is highly safe and effective for elderly patients with early-stage non-small cell lung cancer. Int J Radiat Oncol Biol Phys 2017;98:900-7.

26. Kreinbrink P, Blumenfeld P, Tolekidis G, Sen N, Sher D, et al. Lung stereotactic body radiation therapy (SBRT) for early-stage non-small cell lung cancer in the very elderly ( $\geq 80$ years old): extremely safe and effective. J Geriatr Oncol 2017;8:351-5.

27. Cassidy RJ, Patel PR, Zhang X, Press RH, Switchenko JM, et al. Stereotactic body radiotherapy for early-stage non-small-cell lung cancer in patients 80 years and older: a multi-center analysis. Clin Lung Cancer 2017;18:551-8.e6.

28. Videtic GMM, Woody NM, Reddy CA, Stephans KL. Never too old: a single-institution experience of stereotactic body radiation therapy for patients 90 years and older with early stage lung cancer. Pract Radiat Oncol 2017;7:e543-9.

29. Chang JY, Senan S, Paul MA, Mehran RJ, Louie AV, et al. Stereotactic ablative radiotherapy versus lobectomy for operable stage I nonsmall-cell lung cancer: a pooled analysis of two randomised trials. Lancet Oncol 2015;16:630-7.

30. Guckenberger M, Aerts JG, Van Schil P, Weder W. The American Society of Clinical Oncology-endorsed American Society for Radiation Oncology Evidence-Based Guideline of stereotactic body radiotherapy for early-stage non-small cell lung cancer: an expert opinion. J Thorac Cardiovasc Surg 2019;157:358-61.

31. Whitson BA, Groth SS, Duval SJ, Swanson SJ, Maddaus MA. Surgery for early-stage non-small cell lung cancer: a systematic review of the video-assisted thoracoscopic surgery versus thoracotomy approaches to lobectomy. Ann Thorac Surg 2008;86:2008-16; discussion 2016-8.

32. Zhang B, Zhu F, Ma X, Tian Y, Cao D, et al. Matched-pair comparisons of stereotactic body radiotherapy (SBRT) versus surgery for the treatment of early stage non-small cell lung cancer: a systematic review and meta-analysis. Radiother Oncol 2014;112:250-5.

33. Wang SW, Wang XX, Zhou Q, Xu YT, Xia WJ, et al. Stereotactic ablative radiotherapy versus lobectomy for stage I non-small cell lung 
cancer: a systematic review. Thorac Cancer 2018;9:337-47.

34. Scotti V, Bruni A, Francolini G, Perna M, Vasilyeva P, et al. Stereotactic ablative radiotherapy as an alternative to lobectomy in patients with medically operable stage I NSCLC: a retrospective, multicenter analysis. Clin Lung Cancer 2019;20:e53-61.

35. Robinson CG, DeWees TA, El Naqa IM, Creach KM, Olsen JR, et al. Patterns of failure after stereotactic body radiation therapy or lobar resection for clinical stage I non-small-cell lung cancer. J Thorac Oncol 2013;8:192-201.

36. Chen H, Laba JM, Boldt RG, Goodman CD, Palma DA, et al. Stereotactic ablative radiation therapy versus surgery in early lung cancer: a meta-analysis of propensity score studies. Int J Radiat Oncol Biol Phys 2018;101:186-94.

37. Khakwani A, Harden S, Beckett P, Baldwin D, Navani N, et al. Post-treatment survival difference between lobectomy and stereotactic ablative radiotherapy in stage I non-small cell lung cancer in England. Thorax 2020;75:237-43.

38. Cao C, Wang D, Chung C, Tian D, Rimner A, et al. A systematic review and meta-analysis of stereotactic body radiation therapy versus surgery for patients with non-small cell lung cancer. J Thorac Cardiovasc Surg 2019;157:362-73.e8.

39. Ezer N, Veluswamy RR, Mhango G, Rosenzweig KE, Powell CA, et al. Outcomes after stereotactic body radiotherapy versus limited resection in older patients with early-stage lung cancer. J Thorac Oncol 2015;10:1201-6.

40. Grills IS, Mangona VS, Welsh R, Chmielewski G, McInerney E, et al. Outcomes after stereotactic lung radiotherapy or wedge resection for stage I non-small-cell lung cancer. J Clin Oncol 2010;28:928-35.

41. Wu J, Bai HX, Chan L, Su C, Zhang PJ, et al. Sublobar resection compared with stereotactic body radiation therapy and ablation for early stage non-small cell lung cancer: a national cancer database study. J Thorac Cardiovasc Surg 2019; doi: 10.1016/j.jtcvs.2019.11.132.

42. Yerokun BA, Yang CJ, Gulack BC, Li X, Mulvihill MS, et al. A national analysis of wedge resection versus stereotactic body radiation therapy for stage IA non-small cell lung cancer. J Thorac Cardiovasc Surg 2017;154:675-86.e4. 